\title{
Harnessing the Human Rights Reasonableness Principle for Access to Medicine*
}

\author{
Shamiso Zinzombe \\ DOI: $10.21827 / 5 a 86 a 8 c 6301 b d$
}

\begin{abstract}
Keywords
ACCESS TO MEDicine; Pharmaceutical Corporations; ReAsonableness Principle; INTEllectual Property; ECONOMic, Social AND CUltural Rights; ThE Right to HEALth; IN-TRANSIT; INTERCEPTION; SEIZURE.
\end{abstract}

\begin{abstract}
The reasonableness principle has come to the fore in human rights law with the entry into force of a much anticipated Optional Protocol to the International Covenant on Economic, Social and Cultural Rights. While the Committee on Economic, Social and Cultural Rights, monitoring implementation of the treaty, has maintained a similar principle in documents such as its statements, this is the first time that the reasonableness principle has been formally enumerated in human rights treaty law. The manner in which pharmaceutical corporations exploit patents in the context of the human right entitlement to access medicine is an interesting area to examine using this principle. The application of patents to medicine is controversial and rightly challenged for creating a system of innovation that prioritises profits over people. This unconscionable system is one for which activists, scholars and commentators are correctly calling for a human rights based open system of innovation that ensures access to medicine for all in need. This article, however, explores strategies that could be used in the meantime. These strategies speak to some causes of this problem related to decisions to use intellectual property in certain contexts. For example, the seizure of generic medicine en route from India to Brazil whilst in transit in Rotterdam, the use of multiple patents through strategies known as 'evergreening', patent 'thicketing' or 'clustering' to thwart the entry of generic medicine, or restrictions on voluntary licences such as geographic restrictions that prevent supply of medicine to certain territories. At the same time, it is worthwhile noting that the Agreement on Trade-Related Aspects of Intellectual Property contains provisions which could work with the reasonableness principle. Thus, this article argues, in addition to other principles advanced in the human rights community in this area, it is also possible to apply a reasonableness principle to the use of intellectual property in the area of medicine. It does so by using seizure of in-transit generic medicine as a case study with which to extrapolate the potential application of the reasonableness principle. This paper sets out an introduction, explains the practice of intercepting or seizing generic medicine in-transit, discusses the reasonableness principle and explores the reasonableness principle as a mechanism to hold pharmaceutical corporations to account in order to promote, rather than hinder access to medicine.
\end{abstract}

\footnotetext{
This article was peer-reviewed.
}

$\mathrm{PhD}$ Researcher, Erasmus University Rotterdam, this article is based in parts on a paper presented at a seminar hosted by the Netherlands School of Human Rights Research Working Group on Economic, Social and Cultural Rights and Erasmus Observatory on Health Law on 22 November 2013 in Rotterdam. The author is grateful for any comments received from participants and acknowledges any mistakes are her own. 


\section{Introduction}

Over the past two decades, serious problems associated with the way in which intellectual property is exercised over medicine have been observed and well documented. ${ }^{1}$ This has also highlighted a continuing need for a different system, to ensure that innovation and access to medicine take place in tandem consistently with international human rights legal norms, like those enumerated in the right to health. ${ }^{2}$ This article, however, considers what else could be done, in the meantime, to promote access within the current limited framework. It does so by looking at a case study concerning the practice of intercepting in-transit generic medicine. ${ }^{3}$ It is a matter that has engaged the interest not only of the immediately affected nations of India and Brazil ${ }^{4}$ but also other medicine producing nations, such as Canada and Japan. ${ }^{5}$ Consultations on disputes concerning the practice of interception are presently ongoing at the World Trade Organization (WTO).

This article examines the potential of the reasonableness principle as a mechanism to promote access to medicine, in the context of some pharmaceutical corporate activities in relation to the manner in which they use patents. Sources of law of the reasonableness principle in international law include jurisprudence from the International Court of Justice and now the Optional Protocol to the International Covenant on Economic, Social and Cultural Rights. The activity studied in this article is the practice whereby pharmaceutical companies direct customs officials to intercept or seize in-transit generic medicine destined for developing countries. This paper asks how the reasonableness principle might be harnessed in order to promote access to medicine in relation to the manner in which pharmaceutical corporations exploit patents on medicine. How can the reasonableness principle inform law and policy makers? What should pharmaceutical corporations do in order to integrate elements of the reasonableness principle into their decision-making processes in order to avoid taking decisions and executing actions that impede access to medicine, like intercepting or seizing generic medicine in-transit to developing countries? Thus, this paper outlines the practice of intercepting in-transit generic medicine, discusses the reasonableness principle, and considers ways in which the reasonableness principle might be a useful way to address this particular problem. This is an exercise, which may also serve as an interesting template for other issues raised by the current system of innovation and access to medicine.

1 Hestermeyer, H, Human Rights and the WTO: The Case of Patents and Access to Medicines, (Oxford University Press, New York, 2007).

2 t'Hoen, E, The Global Politics of Pharmaceutical Monopoly Power, (AMB, Diemen, 2009).

3 Baker, BK, "Settlement of India/EU WTO Dispute Re Seizures of Generic Medicines: Why the proposed EU Border Regulation Isn't Good Enough", PIJIP Research Paper Series (2012) at $<$ digitalcommons.wcl.american.edu/research> (accessed 16 September 2015), 3.

4 World Trade Organization (WTO), European Union and a Member State - Seizure of Generic Drugs in transit (Request to Join Consultations by Brazil), WT/DS409/1/IP/D/29 and G/L/922 (Brazil-EU Seizure of Generic Drugs), 19 May 2010; WTO European Union and a Member State - Seizure of Generic Drugs in transit (Request to Join Consultations by India), WT/DS408/1/G/L/921 and IP/D/28 (India-EU Seizure of Generic Drugs), 19 May 2010.

5 WTO, European Union and a Member State - Seizure of Generic Drugs in transit (Request to Join Consultations by Canada), WT/DS409/2, 1 June 2010; WTO, European Union and a Member State - Seizure of Generic Drugs in transit (Request to Join Consultations by Japan), WT/DS409/7, 3 June 2010. 


\section{The Practice of Seizing In-Transit Generic Medicine}

An illustration of the practice of seizing in-transit generic medicine is the incident that took place on 4 December 2008. While en route from India to Brazil, a consignment of the generic hypertension medicine, Losartan, was seized in the Netherlands Port of Rotterdam. The public authorities of the Netherlands' customs services carried out the seizure. The consignment was in-transit, thus the jurisdiction of the Netherlands customs authorities over such goods was questionable. This particular consignment was 570 kilograms and earmarked for 300, 000 Brazilian people in need of this particular hypertension treatment. The consignment was detained for 36 days before it was released and returned to India. This deprived the 300, 000 Brazilians for whom it was intended from accessing it. This seizure took place at the behest of the pharmaceutical company holding the patent for the non-generic form of medicine, in the Netherlands. In this case the company was Merck, a large American multinational company. The reason for the seizure was an allegation that the medicine was counterfeit medicine, which violated the intellectual property rights of Merck, ${ }^{6}$ as protected by the Agreement on Trade- Related Aspects of Intellectual Property Rights (TRIPS Agreement/TRIPS) ${ }^{7}$ a treaty that makes up part of the WTO body of law. The Netherlands, which is a member state of the WTO, was apparently obliged to comply with TRIPS. Losartan was not patent protected in India, nor in Brazil, the two countries involved in trading the medication at the time of its seizure. ${ }^{8}$

Generic medicine is an important addition to a health system because it is medicine equivalent to patented medicine in safety, quality, efficacy, and, at a more affordable, often considerably reduced price. Counterfeit medication, a serious cause of concern for all countries committed to health, is not the same thing as generic medicine. Counterfeit medicine is detrimental to health and has no proven quality, safety and efficacy. ${ }^{9}$ This was not the case with the Losartan consignment at issue. It was made by the Indian generic company Dr Reddys Laboratories Ltd. This seizure took place notwithstanding the fact that within the TRIPS framework for public health purposes, countries also have a right to use generic medication. This seizure was not the first, nor was it the last such seizure of generic medicine. According to prominent international non-governmental organisations working on access to medicine in 2008, at least 17 shipments of generic medicine were detained in Rotterdam alone. Rotterdam, or the Netherlands for that matter, is also not the only port or country to detain generic medicine in-transit. ${ }^{10}$

6 De Volkskrant, Vos, C, Patently Cruel, 19 June 2009, <volkskrant.nl> (accessed 20 October 2011) (Vos); International Centre for Trade and Sustainable Development, "Dutch Seizure of Generic Drugs Sparks Controversy", 13(3) Bridges Weekly Trade News Digest (2009) 5 at <ictsd.org> (accessed 20 October 2011) (Bridges Weekly Trade News Digest (2009) 5); WTO, European Union and a Member State - Seizure of Generic Drugs in transit (Request to Join Consultations by Brazil), WT/DS409/1/IP/D/29 and G/L/922 (Brazil-EU Seizure of Generic Drugs), 19 May 2010, 1; WTO, European Union and a Member State - Seizure of Generic Drugs in transit (Request to Join Consultations by India), WT/DS408/1/G/L/921 and IP/D/28 (India-EU Seizure of Generic Drugs), 19 May 2010, 4.

7 Agreement on Trade-Related Aspects of Intellectual Property Rights, 15 April 1994,LT/UR/A-1C/IP/1 (TRIPS).

8 Vos, Bridges Weekly Trade News Digest, supra nt 6, 5.

9 The Telegraph, Akhtar, S, Blowing the whistle on fake drugs, 31 August 2009, at <telegraphindia.com> (accessed 15 December 2011). Generic Companies and Countries that produce generic medicine such as India are also concerned about fake drugs which are identified because they lack the correct pharmaceutical composition and can thus be detrimental to health.

10 Vos, Bridges Weekly Trade News Digest supra nt 7, 5; WTO, European Union and a Member State Seizure of Generic Drugs in transit (Request to Join Consultations by Brazil), WT/DS409/1/IP/D/29 and G/L/922 (Brazil-EU Seizure of Generic Drugs), 19 May 2010, 1; WTO, European Union and a Member 
Finally, this seizure took place notwithstanding the fact that the TRIPS Agreement does not oblige its Member States to institute border proceedings against goods in-transit, like medicine. ${ }^{11}$ Thus, States are not required to institute border proceedings on in-transit medicine. However, some scholars also point out that it also does not preclude member States from doing the same. ${ }^{12}$ Hence, TRIPS does not prevent member States from instituting such measures. This appears to create a gap in law or suggest that the law is silent on this issue, with the consequence that some States argue that they may institute such measures without falling foul of TRIPS. At the same time, even if TRIPS may be regarded as neither obliging nor precluding in-transit proceedings, patents apply territorially and not extra-territorially. Thus, patents apply only in the territory in which they have been granted. International scholars are correct in their unanimous assertion that intercepting in-transit generic medicine, on the basis of a patent protected in the jurisdiction of a third party, contravenes the territorial application of patents within TRIPS. ${ }^{13}$ Moreover, whether or not intellectual property can be said to have been violated, international scholars also rightly argue, should depend on the law of the trading nations and not that of a third party. ${ }^{14}$ Finally, it is also important to point out, as discussed by Baker, the Memorandum of Understanding between India and the European Union. Baker states that it provides, '[p]ursuant to the announced Understanding, the European Union will no longer intercept in-transit generic medicines unless there is adequate evidence to satisfy customs authorities that there is a substantial likelihood of diversion of such medicines to the EU market. ${ }^{15}$

As seen above, much of the focus has been on the role of the State, yet it is also important to examine the role of the pharmaceutical company in this context. It is an important factor, as interception often takes place in response to a complaint from pharmaceutical companies, and in a few instances customs officials acted in the absence of such a complaint. ${ }^{16}$ This raises the question, even if TRIPS law were silent or had a gap: is this in any event a reasonable way for pharmaceutical companies to conduct themselves given the impact on access to medicine?

State - Seizure of Generic Drugs in transit(Request to Join Consultations by India), WT/DS408/1/G/L/921 and IP/D/28 (India-EU Seizure of Generic Drugs), 19 May 2010, 4.

11 Article 51 [see especially footnote 13], Agreement on Trade Related Aspects of Intellectual Property Rights, 15 April 1994,LT/UR/A-1C/IP/1; Ho, C, Access to Medicine in the Global Economy: International Agreements on Patents and Related Rights (Oxford University Press, 2011), 303-305, 314; However, the United Nations Convention on the Law of the Sea (adopted 10 December 1982, entry into force 16 November 1994) 1833 UNTS 397, regulates treatment of goods in-transit and during innocent passage by customs officials. It lists the circumstances in which customs authorities may interfere with such goods. Alleged violations of intellectual property rights are not listed as a ground. This is important because the skeletal facts shared with the public over the seizures of generic medicine in Rotterdam do not indicate whether these provisions would be excluded. The TRIPS Agreement should have specified this if it intended such powers.

12 Ibid.

13 Baker, supra nt 4, 6-7. He also outlines other legal arguments relevant to this discussion including a violation of international human rights law on access to medicine.

$14 \quad I d, 7$.

$15 \quad I d, 3$.

$16 \quad I d, 5$. 


\section{The Reasonableness Principle}

Reasonableness is a term with legal effect used in international law by at least two different institutions. The International Court of Justice (ICJ) and the Committee on Economic, Social and Cultural Rights (CteeESCR) have both used it in differing contexts. It is also very popular in South African constitutional law jurisprudence in the area of economic, social and cultural rights. At the same time, it is important to mention, the TRIPS Agreement may very well have a corresponding yet hitherto undeveloped reasonableness principle. Each of these representations of reasonableness, in domestic and international law, shall now be discussed in turn.

\section{III.1. The International Court of Justice}

The Barcelona Light and Traction Company case $^{17}$ is one such example where reasonableness was used by the ICJ in order to settle a legal question before it. In particular, this term was used in the Court's consideration of an argument raised by Belgium, in an attempt to found standing on behalf of certain shareholders that were its nationals. Belgium argued the principle of equity should be enough to found jurisdiction. The court did not accept that the principle of equity founded jurisdiction in this case. In reaching this decision, it considered what the practical consequences might be if equity were to be applied. The court found applying the principle of equity would be unreasonable because the effect would be impractical. ${ }^{18}$

One reason the effect would be impractical was because quantitatively, equity did not allow for distinctions. First, companies typically have various unequal shares among shareholders ranging from small (1\% share) to a large (90\%) share. Applying equity, the state would be allowed to intervene in respect of both instances; the size of the share would not be the deciding factor. However, the point for the Court was that what mattered was that international law should be applied reasonably. This included consideration of the impact on the ground. Second, applying the argument of the Belgian government, given also the frequency in which shares, including international shares, changed hands would make international law simply unworkable. ${ }^{19}$ Gros $\mathrm{J}$, in his dissenting opinion, also noted that in such matters reasonableness in law and economics should be applied. ${ }^{20}$

The Barcelona Light and Traction Company case introduces the idea of reasonableness in the way in which international law is applied. Moreover, the manner in which the Court applied this concept suggests reasonableness as a principle that has certain practical implications. This may be derived from the Court's main judgment and a dissenting opinion to reject equity given the impact on the ground of applying it in that context.

17 International Court of Justice, Barcelona Light and Traction Company case (Belgium v Spain) ICJ Reports 1970, 5 February 1970 (Barcelona Light and Traction Company case).

Id, paras 93-94, 96.

Ibid.

$I d$, (Dissenting Opinion, Gros J), para 20. 


\section{III.2. Committee on Economic, Social and Cultural Rights (CteeESCR)}

The CteeESCR has clearly embraced a reasonableness principle through two different international legal instruments. Prior to the Optional Protocol to the International Covenant on Economic, Social and Cultural Rights (OP ICESCR) ${ }^{21}$ a reasonableness principle was used in the Committee's statements of its understanding of the legal term 'maximum available resources'. Of course in the OP ICESCR the reasonableness principle is expressly articulated as a mechanism which the Committee shall use when assessing communications.

Article 2(1) of the International Covenant on Economic, Social and Cultural Rights (ICESCR) provides,

Each State Party to the present Covenant undertakes to take steps, individually and through international assistance and co-operation, especially economic and technical, to the maximum of its available resources, with a view to achieving progressively the full realization of the rights recognized in the present Covenant ${ }^{22}$

During the process of negotiations for the OP ICESCR, the CteeESCR issued a statement with regard to the interpretation of the term, 'maximum available resources'. In the statement the CteeESCR also discussed reasonableness; stating, in a nonexhaustive list, that

[i]n assessing whether they are "adequate" or "reasonable", the Committee may take into account, inter alia, the following considerations:

(a) the extent to which the measures taken were deliberate, concrete and targeted towards the fulfilment of economic, social and cultural rights;

(b) whether the State party exercised its discretion in a non-discriminatory and nonarbitrary manner;

(c) whether the State party's decision (not) to allocate available resources is in accordance with international human rights standards;

(d) where several policy options are available, whether the State party adopts the option that least restricts Covenant rights;

(e) the time frame in which the steps were taken;

(f) whether the steps had taken into account the precarious situation of disadvantaged and marginalized individuals or groups and, whether they were non-discriminatory, and whether they prioritized grave situations or situations of risk. $^{23}$

21 UN General Assembly (UNGA), Optional Protocol to the International Covenant on Economic, Social and Cultural Rights adopted 10 December 2008, entered into force 5 May 2013, Resolution A/RES/63/117.

22 International Covenant on Economic, Social and Cultural Rights (ICESCR) 16 December 1966, United Nations, Treaty Series, vol. 993, p. 3 [emphasis added].

23 UNCHR 'Statement An Evaluation of the Obligation to take steps to the "Maximum available resources" under an Optional Protocol to the Covenant' 10 May 2007 UN Doc E/C.12/2007.1, para 8; see also Griffey, B, "The 'Reasonableness' Test: Assessing Violations of State obligations under the Optional Protocol to the International Covenant on Economic, Social and Cultural Rights", 11(2) Human Rights Law Review (2011) 275,321-322; treats this as the Ctee ESCR's approach to the 
Article 8(4) of the OP ICESCR provides,

When examining communications under the present Protocol, the Committee shall consider the reasonableness of the steps taken by the State Party in accordance with part II of the Covenant. In doing so, the Committee shall bear in mind that the State Party may adopt a range of possible policy measures for the implementation of the rights set forth in the Covenant. ${ }^{24}$

Based on the text of Article 8(4), reasonableness is a principle that applies to measures adopted by States as they implement provisions of the ICESCR. Moreover, scholars agree that the reasonableness principle presupposes that for the most part there is more than one option for the State to choose from. ${ }^{25}$ According to Porter this includes recognising various actors, including private actors, and other systems of entitlement that are involved in the implementation of economic, social and cultural rights and in failures associated with such implementation. ${ }^{26}$ The reasonableness principle is thus also applied to private actors, like a pharmaceutical corporation, in the way in which their activities impact the realisation of an economic, social and cultural right.

Further, human dignity and equality are central to assessment of the reasonableness principle. ${ }^{27}$ Another way of putting it is that the centrality of the right holder's context is important. Porter and Liebenberg describe it in this way

[t] he analysis [of what is reasonable] must be framed by and fully grounded in the context of the petitioner's circumstances, the content of the right and the broader values and purposes of the ICESCR.... [it is] the standard of decision-making that is required for full compliance with the ICESCR, both procedurally and substantively, with respect to the content of the petitioners' rights and the use of the maximum available resources. ${ }^{28}$

The concept and implementation of any policy or programme must be also reasonable. Therefore, means and outcomes matter too. ${ }^{29}$ Porter and Liebenberg also identify the criteria useful in establishing substantive compliance with the Article 8(4) principle. These criteria are: availability, accessibility, acceptability and adaptability. ${ }^{30}$ With the exception of adaptability these appear to be similar to the availability, accessibility, acceptability and quality (AAAQ) criteria in General Comment $14 .{ }^{31}$ In the most recent

reasonableness standard and remarks on its similarity to the same Committee's long-established approach to interpreting the ICESCR.

24 Article 8(4), International Covenant on Economic, Social and Cultural Rights; Porter, B, "The Reasonableness of Article 8 (4) - Adjudicating Claims from the Margins", 27(1) Nordic Journal of Human Rights (2009) 39, 52; also observes the Optional Protocol to the International Convention on Disability also has a principle of reasonable accommodation in relation to disability.

25 Id, 52-53; ESCR-NET, Porter, B and Liebenberg, S, Consideration of the merits Under the OP-ICESCR: Reasonableness Review under 8 (4) and the Maximum available resources standard Notes for discussion at the Workshop on Strategic Litigation under the OP-ICESCR, at <escr-net.org> (accessed 31 October 2012), 1.

26 Porter, supra nt 21, 50, 52-53.

$27 \quad I d, 51$.

28 Porter and Liebenberg, supra nt 22, 5, 6, 8.

29 Porter, supra nt 21, 51.

30 Porter and Liebenberg, supra nt 22, 8.

31 General Comment 14 paras 12, 33, 34, 35, Koch, IE, "Dichotomies, Trichotomies or Waves of Duties?", 5(1) Human Rights Law Review (2005) 81, 81-82, 103; the value of the tripartite obligations is as an analytical tool. 
General Comment on the ICESCR, the right to take part in cultural life, the concept of adaptability is introduced in the AAAQ framework. There adaptability refers inter alia to the flexibility and relevance of the programmes and policies adopted by the state in relation to specific cultures. ${ }^{32}$

Griffey $^{33}$ and Porter and Liebenberg ${ }^{34}$ agree that the inspiration for this article on reasonableness in the OP ICESCR is the Grootboom Case. ${ }^{35}$ Interpretation of what this principle means is already the topic of much debate, as the writing of these three authors indicates. However, all three authors reject the narrow interpretation that would relegate reasonableness to nothing more than a standard of procedural judicial review. ${ }^{36}$

\section{III.3 TRIPS}

It may be worthwhile to mention that the TRIPS Agreement has a notion of unreasonableness specifically intended for the use of patents. It provides for a limited exception that fulfils this criteria: 'such exceptions do not unreasonably conflict with a normal exploitation of the patent and do not unreasonably prejudice the legitimate interests of the patent owner, taking account of the legitimate interests of third parties' ${ }^{37}$

Moreover, reasonableness also appears with regard to Article 31 TRIPS Agreement. The article, in particular, references 'reasonable commercial terms and conditions', 'reasonable period of time' and 'reasonably practicable'. ${ }^{38}$ In the Canadian Stockpiling Case the panel had an opportunity to interpret the term reasonableness with regard to Article 30. However, it elected not to do so because it reached its findings based on other criteria. ${ }^{39}$ Even so, the interventions of third party States provide some suggestion of how at least some member States interpret reasonableness in Article 30 TRIPS Agreement.

32 UN Committee on Economic, Social and Cultural Rights 'General Comment 21' (21 December 2009) UN Doc E/C.12/GC/12 para 16 (d).

33 Griffey, supra nt 20, 302.

34 Porter and Liebenberg, supra nt 22, 1-2; share their experience in contributing to the drafting process of the OP ICESCR, they note that Article 8(4) is inspired by para 41 of the Grootboom Case of which all participants were in agreement. They also note,

It has been read by some as a strong affirmation of substantive rights that require positive measures well beyond, but including, concrete core entitlements. It has been read by others as a relatively weak form of justiciability that substitutes a "good governance" standard of review" for a requirement of "rights compliance", leaving claimants with "a right to a reasonable housing policy" rather than a right to adequate housing." Differences in interpretation of what the reasonableness standard means.

35 Government of the Republic of South Africa and Others v Grootboom and Others [2000] ZACC 19.

36 Porter and Liebenberg, supra nt 22, 2-5; Griffey, supra nt 20, 305-307; he further points out that the United Kingdom's notion of unreasonableness limited to judicial review was also vetoed by the European Court of Human Rights.

37 Article 30 Agreement on Trade Related Aspects of Intellectual Property Rights [emphasis added].

38 Article 31 (b) Agreement on Trade Related Aspects of Intellectual Property Rights.

39 WTO, Canada - Patent Protection of Pharmaceutical Products (Canadian Stockpiling Case) WT/DSI14/R, 17 March 2000, 152-153, 155-162, 164-165, 168 the panel had to decide whether Canadian stockpiling and regulatory review provisions satisfied TRIPS Article 30 which provides for limited exceptions to patent rights conferred. In terms of law the panel interpreted the term limited exception narrowly. It determined an exception that results in a small attenuation of the right complied with the standard. Factually, stockpiling was regarded as falling outside the bounds of a limited exception whereas the regulatory review exception was found to fall within the permissible bounds of the exception; Articles 30, 31, Agreement on Trade Related Aspects of Intellectual Property Rights; Doha Declaration notwithstanding the Canadian Stockpiling Case, the Doha Declaration paragraph 5 (a) provides weight in support of a broader interpretation of Article 30 for public health purposes, at least provided that it is consistent with TRIPS Agreement objectives and principles . 
Australia argued that the provision contained a reasonableness test. In this regard it considered the, 'steps involved in obtaining regulatory approval....were allowable exceptions under Article 30, since any detriment to the patentee was reasonable'. ${ }^{40}$ Furthermore, the context of the application of this test was in their view, '[t]he range of permissible Article 30 exceptions should be determined with reference to the overall objectives and balance of interests in the TRIPS Agreement and the availability of other forms of authorized use'. ${ }^{41}$ Colombia submitted that reasonableness should be established as follows,

[f]or an exception to have an unreasonable impact on the right to exploitation of the patent, it would have to unjustifiably and substantially affect the rights derived by the patent owner. The word "unreasonable" meant "going beyond the limits of what is reasonable" as would be the case of: (i) an unjustified exception; (ii) an exception whose scope went beyond the rights directly connected with the aim pursued; or (iii) an exception applied in such a way as to damage substantially the economic right derived from the exploitation of the patent. ${ }^{42}$

Cuba argued, "exceptions were legitimate if they were considered "reasonable". However, the qualification of "reasonable" was given by national law, within its own framework, in accordance with Article 1.1 of the TRIPS Agreement'. ${ }^{43}$ Switzerland argued 'unreasonable' referenced an unjustified limitation of the patent. ${ }^{44}$ Depending on how this is eventually interpreted by the WTO DSB, it appears to provide, if not explicitly at least implicitly, for some form of reasonableness test or assessment mechanism. The exception in Article 30 allows for legitimate third party interests to override the rights conferred on a patent when certain criteria are satisfied. The only prima facie criteria are that the interests of third parties should be legitimate and reasonableness should be applied to the impact of these interests on the rights conferred to the patent holder. Thus, for as long as the impact is reasonable, then the limitation based on that legitimate interest should be acceptable. In the author's opinion, it would be consistent with international law if this provision were interpreted in light of other reasonableness standards in operation.

\section{III.4. Republic of South Africa}

The Grootboom Case, as already mentioned above, was the first case in which the reasonableness standard was applied by the constitutional court. ${ }^{45}$ The first case to concern the right to health in which the reasonableness principle was applied is the famous $T A C$ judgment. ${ }^{46}$ This case concerned, access to Nevirapine, a medicine given to mothers at point of birth in order to prevent transmission of HIV/AIDS to the child. Nevirapine was taken as a single dose in contrast to medicine taken regularly to treat a chronic condition. The pharmaceutical manufacturer offered the government a free supply of the medicine for a period of five years. The government, however, created a

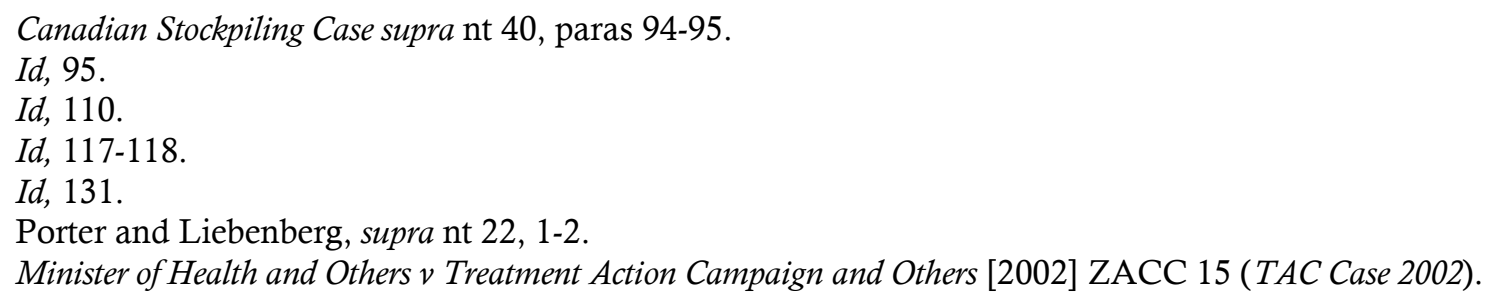


policy wherein the medicine was only made freely available to the private sector. However, only 18 sites were selected to make the medicine available in the public sector. These 18 sites were also treated as clinical trial sites by the government. It was this decision to restrict access in the public sector that brought this case before the constitutional court. ${ }^{47}$

The government articulated four reasons for limiting access to 18 sites. First, the government claimed that it did not have the resources to roll out a comprehensive package which included antibiotics and formula for the child beyond the current 18 sites. Second, it raised 'efficacy' concerns; in particular it feared patients may develop resistance to Nevirapine and other antiretroviral drugs (ARVs). The third reason raised by the government was safety concerns related to the drug. Finally, fourth, the government was concerned whether it would be appropriate to provide Nevirapine without the other components that make up the planned comprehensive package. ${ }^{48}$

Applying the reasonableness standard, to the policy of the government, in this case the Court reinforced the line adopted in the Grootboom Case. It affirmed the notion that the Constitution places a negative duty on the State and all other persons not to impair or prevent, in this case, the right to access healthcare and services. Thus, when the Court evaluates challenges made against measures taken by the State, for instance, this principle applies. ${ }^{49}$ One may also highlight the obiter dictum of the Court that this approach applies in respect of private persons, particularly given the Bertie van $Z y l$ case, which affirms linkages between a constitutionally protected right (the right to freedom and security of the person), and the duty of a private actor like private security companies whose role complemented policing functions. ${ }^{50}$ Furthermore, the Court's evaluation of what is reasonable is context-specific and evidence-based in light of the impact on the right. For example, as noted above, one of the reasons that the government did not want to provide medicine to the public was because it was concerned about the efficacy of the medicine. However, scientific material presented by both parties showed this claim to have no evidentiary base. It found Nevirapine worked; however, if the mother breast-fed the child then it was likely, in some cases, that the child might contract the disease from this act. ${ }^{51}$ Thus, reasonableness also requires an examination of any evidence including technical data to see whether or not it supports the claim in that context.

Moreover, the Court discussed considerations it identified as relevant to reasonableness. These considerations included: 1 . the consequence of the action or conduct; 2 . identifying who is impacted by the conduct; 3 . why and how the person has been impacted; and 4 . the extent of the impact on the individual. In the case, the consequence of the State's policy was to deny access to Nevirapine to mothers and their new-borns that could not afford to pay for it and lived outside the 18 research sites. The consequences of the impact were that their children were denied lifesaving treatment. ${ }^{52} \mathrm{~A}$ programme to realise economic, social and cultural rights is also reasonable because it is, 'balanced and flexible and make[s] appropriate provision for attention to...crises and to

$47 \quad I d$, paras $2,4-5,10-12,17-19,25,44-45,47,50$.

$48 \quad I d$, paras 51-55.

$49 I d$, paras 36, 46. It may also be relevant to note that the pharmaceutical manufacturer of the medicine Nevirapine had offered it to RSA authorities for free for a period of five years.

$50 \quad$ Bertie van Zyl (PTY) Ltd and Montina Boerdery (PTY) Ltd v Minister for Safety and Security and Four Others Z ACC 11.

51 TAC Case, supra nt 47, paras 57-63 consider the evidence in relation to the other arguments brought by the government.

$52 \quad I d$, paras $67-68,70,72-73$. 
short, medium and long term needs. A programme that excludes a significant segment of society cannot be said to be reasonable'. ${ }^{53}$

Thus, from the Grootboom Case and the TAC Case the following elements are central to a reasonableness evaluation of a programme designed to implement or realise economic, social and cultural rights: context, evidence, impact, identity of the person or group impacted, degree of impact, balance and flexibility of the programme and inclusivity.

In the Water Case ${ }^{54}$ the Court added to its articulation of the reasonableness approach. To briefly explain, the Water Case concerned the introduction by the Johannesburg City Council of a new policy for providing water services in Soweto. The new policy had three kinds of water services, one of which included a prepaid meter. The policy at the time of proceedings was at the pilot phase. ${ }^{55}$ In its reasoning, the Court made the following important statements with regard to the application of the reasonableness standard,

[t]he purpose of the constitutional entrenchment of social and economic rights was thus to ensure that the state continue to take reasonable legislative and other measures progressively to achieve the realisation of the rights to the basic necessities of life. It was not expected, nor could it have been, that the state would be able to furnish citizens immediately with all the basic necessities of life. Social and economic rights empower citizens to demand of the state that it acts reasonably and progressively to ensure that all enjoy the basic necessities of life. In so doing, the social and economic rights enable citizens to hold government to account for the manner in which it seeks to pursue the achievement of social and economic rights. ${ }^{56}$

There is no expectation of immediate gratification or rather satisfaction of a basic necessity. However, there is ensured a right to hold the State to account in relation to activities it organises with a view to making such a right a reality. The State, in this regard, is expected to act reasonably in its planning among other measures designed to implement economic, social and cultural rights. This is a continuous process. Litigation of economic, social and cultural rights is also a means of holding the government to account. $^{57}$

Moreover, what the right requires will vary over time and context. Fixing a quantified content might, in a rigid and counter-productive manner, prevent an analysis of context. The concept of reasonableness places context at the centre of the enquiry and permits an assessment of context to determine whether a government programme is indeed reasonable. ${ }^{58}$

The context in which the right is realised is also always an important consideration. Flexibility is always required, as is constant evaluation of progress and remedial measures along the way. This too applies to the private sector like a pharmaceutical corporation working in the provision of a right.

\footnotetext{
Id, para 68.

Lindiwe Mazibuko and Others $v$ City of Johannesburg and Others [2009] ZACC 28 (Water Case).

$I d$, paras 9-16.

Id, para 59 [emphasis added].

Id. paras $159-164$.

$58 I d$, paras $60,64,163$. Contexts change and the government always has to be aware of this when implementing a programme. In fact, failure to review policies in light of current contexts would make a policy unreasonable.
} 
According to the Court, positive obligations from economic, social and cultural rights will be enforced in one of the following four ways,

[i]f government takes no steps to realise the rights, the courts will require government to take steps. If government's adopted measures are unreasonable, the courts will similarly require that they be reviewed so as to meet the constitutional standard of reasonableness. From Grootboom, it is clear that a measure will be unreasonable if it makes no provision for those most desperately in need. If government adopts a policy with unreasonable limitations or exclusions, as in Treatment Action Campaign No 2, the Court may order that those are removed. Finally, the obligation of progressive realisation imposes a duty upon government continually to review its policies to ensure that the achievement of the right is progressively realised..$^{59}$

Forman points out that 'reasonableness applies to all elements of governance; not only the content of legislation, programs and policies, but also their manner of implementation' ${ }^{60}$ She makes this observation during her discussion on the interpretation of the reasonableness principle by the Constitutional Court. Thus, taking Forman's observation and the discussion on the elements that make up the reasonableness standard, in relation to ICJ, ICESCR and lessons from South Africa's application of this standard, into account, one may begin to extrapolate its application to pharmaceutical corporations and their use of intellectual property. For example, it is possible to argue that pharmaceutical corporations should integrate these elements into their decisionmaking processes. This would allow them to consider the impact of decisions they are about to make and take remedial action to avert negative impacts on access to medicine. A fuller discussion of this has been set out below in Section 4 of this paper.

\section{III.5 Conclusion on the Reasonableness Principle}

In conclusion, to the discussion on the reasonableness principle, this paper has identified 3 different international law sources of this principle, namely the ICJ, TRIPS and ICESCR. With the exception of TRIPS, each source adds elements which are useful to those seeking to know what the principle is and how it might work in various contexts. It is because the WTO DSB has yet to elaborate on reasonableness in Article 30 and 31 of TRIPS that lessons from this treaty on this point are unknown. However, intervening states in the Canadian Stockpiling Case shared their conceptualisations of this principle. It is from this that it is possible to conclude at a minimum that some States interpret Article 30 TRIPS as mandating development of a reasonableness test or assessment mechanism. In the Barcelona Light and Traction Company Case the ICJ applied a reasonableness principle in its main judgment and one dissenting opinion. Based on the ICJ's application one possible conclusion is that the reasonableness principle relates to practical implications in relation to implementation of certain laws. It is interesting to note the laws at issue concerned economic actors, in particular Belgian shareholders.

The CteeESCR uses a reasonableness principle in its interpretation of the principle 'maximum available resources' and it shall use the reasonableness principle when assessing communications in terms of Article 8(4) OP ICESCR. In relation to the

\footnotetext{
$59 \quad I d$, para 67.

60 L. Forman, 'Ensuring Reasonable Health: Health Rights, the Judiciary and South Africa's HIV/AIDS Policy' Journal of Law, Medicine and Ethics (2005) 711, 714; TAC Case supra nt 47, para 100.
} 
'maximum available resources' reasonableness requires an inquiry into: 1 . the degree to which measures taken were intended to advance an economic, social and cultural; 2 . the absence of arbitrariness and discrimination in the manner in which a State exercised its discretion; 3. compliance with international human rights law when States decide whether or not to allocate resources; 4. selection of the least restrictive means to economic, social and cultural rights if several policy options exist; 5 . the, time frame in which steps were taken; and 6 . whether the steps taken took account of the needs of vulnerable and marginalised individuals and groups.

Article 8(4) OP ICESCR adds further to our understanding by reinforcing previously articulated understandings and adding new elements. For example, scholars anticipate that reasonableness will be applied to measures adopted by a State in its efforts to implement economic, social and cultural rights. Moreover, States should always consider a diversity of options in order to successfully implement economic, social and cultural rights. These two illustrations reinforce the CteeESCR previously articulated understanding of the reasonableness principle. However, Porter in his writing specifies a new element, namely reasonableness that extends to private actors whose activities are part of the States implementation framework in relation to a specific right. A pertinent example, given the case study of seizure of generic medicine, is a pharmaceutical corporation. Porter and Liebenberg also highlight the context of the right holder as a key element to a reasonableness inquiry. Applying this to the context of generic seizures, the right holder in question should be the patients in the importing developing country.

Finally, lessons were also drawn from the domestic experience of South Africa, where the reasonableness principle was first applied in the Grootboom Case. This case is significant because scholars like Griffey, Porter and Liebenberg all agree that it was the inspiration for Article 8(4) OP ICESCR. In the case law of the Constitutional Court the following elements are central to a reasonableness evaluation of a programme designed to implement or realise economic, social and cultural rights: context, evidence, impact, identity of the person or group impacted, degree of impact, balance and flexibility of the programme and inclusivity. An obiter dictum in the TAC Case confirms that reasonableness applies not just to the State but to all other persons. Now that the discussion on the reasonableness principle is concluded, it is appropriate to consider application of the principle in relation to pharmaceutical corporations. The next section examines the potential application of this principle in relation to the case study concerning in-transit seizure of generic medicine and the role of pharmaceutical corporations.

\section{General Application}

Reasonableness in the OP ICESCR is a principle that applies to measures adopted by States as they implement provisions of the ICESCR. Thus, reasonableness applies to the tools, for instance pharmaceutical corporations and their use of intellectual property, as it affects access to medicine. ${ }^{61}$ Hunt, writing with Khosla, includes an illustration of the notion of reasonableness in application in their understanding of the Guidelines for Pharmaceutical Corporations. In particular, they state that in regard to life saving medicine, '[t]he seminal right-to-health responsibility is to take all reasonable steps to make medicine as accessible as possible, as soon as possible, to all those in need, within a viable business model'. ${ }^{62}$

61 Porter, supra nt 25, 50, 52-53; Forman, supra nt 61, 714; TAC Case supra nt 47, para 100.

62 Paul Hunt and Rajat Khosla, 'Are Drug Companies Living Up to Their Human Rights Responsibilities? The Perspective of the Former United Nations Special Rapporteur(2002 -2008)' PLoS Med 7(9) 2010, 2. 
Given this, States should ratify the OP ICESCR because this will strengthen accountability mechanisms in their jurisdictions on economic, social and cultural rights. Further, States should enact legislation and develop policies requiring pharmaceutical corporations to integrate elements of the reasonableness principle into their decisionmaking processes. This will guide pharmaceutical corporations to implement this kind of analysis in their decision-making processes concerning access to medicine. Moreover, it will also guide customs officials placing them in a position to request this kind of information from the pharmaceutical corporation before taking steps, such as intercepting generic medicine.

\section{IV.1 Specific Application - Seizure of Generic Medicine in Transit}

Before in-transit generic medicine is intercepted by customs authorities, a decision has to be taken within a pharmaceutical company to lodge such a complaint. Pharmaceutical companies can incorporate elements of a reasonableness analysis during this decisionmaking process. They can do this by taking note of the common elements of a reasonableness analysis and learning from lessons for specific application of the principle in domestic law.

Based on the analysis set out in Section 3 above, common features of a reasonableness analysis in international law include:

(a) Consideration of the practical application of a legal principle and its impact on the ground in relation to the operation of law;

(b) Consistency with international human rights law;

(c) Whether or not several policy options existed and whether the least restrictive option was selected; and

(d) Consideration of the interests of vulnerable and marginalised groups.

In addition, lessons from the domestic application of a reasonableness principle add considerations of evidence to the framework.

According to the Access to Medicine Index, all pharmaceutical companies assessed are in the process of developing and integrating access to medicine strategies into their structures. The report analysed 'how companies integrate access to medicine into their business strategies, governance structures, management systems and incentive structures'. ${ }^{63}$ It analysed four aspects, two of which present opportunities for corporations to integrate a reasonableness analysis into their decision-making in relation to in-transit generic medicine, in particular managing for access-to-medicine outcomes and access-tomedicine strategy. ${ }^{64}$ Increasingly, there is board representation on access issues and in some cases committees dedicated to access issues composed of personnel from various divisions of the corporation have been created. ${ }^{65}$ These developments demonstrate on the face of it a growing serious commitment and to some extent a concerted effort to contribute toward global access to medicine. This awareness is evolving with respect to

63 Access to Medicine Foundation, REPORT: Access to Medicine Index 2014, at <accesstomedicineindex.org/sites/2015.atmindex.org/files/2014_accesstomedicineindex_fullreport_c lickablepdf.pdf $>$ (accessed 11 December 2015), 41-44.

$64 \quad I d, 41$

65 Id, 45-46. 
their own products, as reflected in the reports. It also needs to extend to some of the ways in which they have interacted with the products of others like initiating interception of intransit generic medicine. Thus, analysing the decision to intercept in-transit generic medicine is something which can be built into evolving strategies to promote access to medicine.

Based on the outline of reasonableness principle, critical questions they need to ask themselves before initiating interception include:

- What, if any is the legal basis of their complaint?

- Who will be impacted by the decision to complain to the authorities?

- How will the intended recipients of the medication be impacted by the decision to complain to the authorities?

- How will the decision to complain to the authorities affect wider overall objectives like increasing access to medicine?

- What evidence do they have to justify a complaint to the authorities?

- Are there alternatives to making a complaint with the authorities?

\section{Conclusion}

This paper explored the role the reasonableness principle could play to promote access to medicine given limitations of the current flawed system of innovation and access. It did so by outlining the case study concerning interception of in-transit generic medicine, discussing the reasonableness principle in international and domestic law and finally, considering the case study in light of the reasonableness principle. Moreover, its focus was on the role of pharmaceutical corporations in relation to their exploitation of intellectual property because generic medicine interception often takes place at their behest, customs officials seldom intercept in-transit generic medicine on their own volition. The case study is important because it illustrates a method by which pharmaceutical companies hinder access to medicine in developing countries through intellectual property use. For example, the generic hypertension medicine Losartan was detained in Rotterdam and returned to India, the exporting State thereby depriving patients in the importing State, Brazil, from accessing it. The prevalence of this practice is such that consultations, which have attracted the attention of other medicine producing nations, are ongoing at the World Trade Organisation concerning the parties India, Brazil and the European Union.

In international law the reasonableness principle has at least three sources of law, namely the jurisprudence of the International Court of Justice, the Agreement on TradeRelated Aspects of Intellectual Property Rights and the CteeESCR and its treaty mechanisms. In comparison to the former two sources the CteeESCR has been developing its conception of the reasonableness principle over the years. This is to such an extent that the principle has been integrated into the Optional Protocol to the Covenant on Economic, Social and Cultural Rights where it will become a key element used by the CteeESCR to examine communications. Finally, lessons from South African domestic constitutional law are also instructive. These lessons are particularly instructive because reasonableness has been used in relation to economic, social and cultural rights, such as the right to health, one of the sources of the human right entitlement to access medicine. Key components of the reasonableness principle in South African law are: 1. context; 2. international human rights law principles; 3 . evidence; 4. alternative policy options; and 5. selecting the least restrictive means. 
States should ratify the Optional Protocol to the Covenant on Economic, Social and Cultural Rights. This will strengthen their accountability mechanisms in favour of the human rights holders they are duty bound to protect, clarify the role of State authorities like customs officials in relation to requests to intercept in-transit generic medicine and determine pharmaceutical corporate decision-making on the same issue. Indications from the Access to Medicine Index are that pharmaceutical companies are increasingly developing access to medicine management strategies and access to medicine is increasingly discussed within the board. This kind of information illustrates a practical way in which pharmaceutical corporations could integrate this into their management thinking. This, however, is only a start; much more still needs to be done given the flawed nature of the innovation and access system to medication and continuing need for medicine on a global scale. 